\title{
UPAYA PENINGKATAN PRODUKTIVITAS RUMPUT LAUT Kappaphycus alvarezii DENGAN MENGETAHUI FAKTOR PENGELOLAAN DI KABUPATEN KONAWE SELATAN PROVINSI SULAWESI TENGGARA
}

\author{
Ruzkiah Asaf, Makmur, dan Rezki Antoni Suhaemi \\ Balai Penelitian dan Pengembangan Budidaya Air Payau \\ Jl. Makmur Dg. Sitakka No. 129, Maros 90512, Sulawesi Selatan \\ E-mail: qiaasaf@gmail.com
}

(Naskah diterima: 19 Maret 2014; Revisi final: 2 Oktober 2014; Disetujui publikasi: 10 November 2014)

\begin{abstract}
ABSTRAK
Rumput laut di Kabupaten Konawe Selatan Provinsi Sulawesi Tenggara merupakan salah satu komoditas unggulan. Metode budidaya yang digunakan adalah metode apung atau tali panjang (long line). Penelitian dilakukan untuk mengetahui produktivitas rumput laut pada beberapa faktor pengelolaan yang dilakukan dalam budidaya rumput laut. Metode survai digunakan dalam penelitian dengan mengajukan kuisioner kepada responden secara terstruktur. Peubah tidak bebas dalam penelitian ini adalah produksi rumput laut, sedangkan faktor pengelolaan budidaya adalah peubah bebas. Untuk memprediksi produksi rumput laut digunakan analisis regresi berganda. Hasil penelitian menunjukkan bahwa produksi rumput laut di Kabupaten Konawe Selatan Provinsi Sulawesi Tenggara berkisar antara 540-2.160 kg/3.000 m² dengan rata-rata $942 \mathrm{~kg}$ kering/3.000 $\mathrm{m}^{2}$. Upaya peningkatan produktivitas rumput laut dapat dilakukan melalui (1) penambahan jumlah tali ris dengan memperhatikan aspek ketersediaan bibit, arus, kondisi dasar perairan, kedalaman, salinitas, kecerahan, pencemaran, dan tenaga kerja; (2) penggunaan bibit rumput laut yang berkualitas baik dan berumur antara 25-35 hari; (3) penambahan jarak antar rumpun dalam tali ris maksimal $30 \mathrm{~cm}$; dan (4) pengontrolan rumput laut secara rutin agar dapat meminimalkan masalah selama budidaya.
\end{abstract}

KATA KUNCI: pengelolaan budidaya, rumput laut, Kabupaten Konawe Selatan

ABSTRACT: Productivity improvement efforts seaweed Kappaphycus alvarezii factors to know the management in district of South Konawe Province of South East Sulawesi. By: Ruzkiah Asaf, Makmur, and Rezki Antoni Suhaemi

South Konawe district seaweed in South East Sulawesi province is one of the leading commodity. Cultivation method is the method of floating or string length (long line). The study was conducted to determine the productivity of seaweed, on a number of factors that management made in the cultivation of seaweed. Survey methods used in the study by submitting a questionnaire to the respondent in a structured. Dependent variable in this study is the seaweed production, while aquaculture management factors are independent variables. To predict the production of seaweed used multiple regression analysis. The results showed that the production of seaweed in South Konawe district South East Sulawesi Province ranged from $540-2,160 \mathrm{~kg} /$ $3,000 \mathrm{~m}^{2}$ with an average of $942 \mathrm{~kg}$ of dry/3,000 $\mathrm{m}^{2}$. Efforts to improve the productivity 
of seaweed undertaken to increase production is to increase the amount of rope ris with respect to some ecological factors, namely the availability of seeds, currents, bottom conditions, depth, salinity, brightness, pollution, and labor. Age seaweed seedlings of good quality must be considered with the harvesting of seeds at the age of 25-35 days, the distance between the clumps increase in maximum ris strap 30 $\mathrm{cm}$. Controlling seaweed should be routinely performed in order to minimize problems during cultivation.

\section{KEYWORDS: management of aquaculture, seaweed, South Konawe}

\section{PENDAHULUAN}

Konawe Selatan merupakan salah satu kabupaten yang memiliki potensi pengembangan usaha budidaya rumput laut di Provinsi Sulawesi Tenggara. Jenis rumput laut yang paling banyak dibudidayakan di perairan Konawe Selatan adalah jenis Kappaphycus alvarezii, karena dapat diusahakan dengan modal rendah, menggunakan teknologi untuk produksi dengan biaya murah, permintaan pasar yang tinggi, siklus produksi yang singkat, metode pascapanen yang tidak terlalu sulit, serta permintaan pasar masih terbuka.

Rumput laut di Kabupaten Konawe Selatan merupakan salah satu komoditas unggulan berdasarkan penetapan komoditas unggulan pada masing-masing wilayah. Komoditas tersebut merupakan komoditas strategis secara nasional, sehingga patut untuk dikembangkan dan merupakan komoditas khas daerah.

Rumput laut $K$. alvarezii dewasa ini sedang giat dikembangkan oleh pemerintah melalui usaha budidaya karena selain dapat meningkatkan pendapatan nelayan juga menjadi sumber devisa negara. Rumput laut yang dibudidayakan bertujuan untuk meningkatkan hasil dalam jumlah yang cukup besar dan kontinu dengan kualitas yang baik terutama untuk kebutuhan ekspor. Permasalahan yang dihadapi dalam budidaya rumput laut di Konawe Selatan adalah tingkat produktivitas masih rendah $<1.000 \mathrm{~kg} / 3.000 \mathrm{~m}^{2}$ disebabkan faktor pengelolaan budidaya yang belum optimal. Oleh karena itu, faktor-faktor pengelolaan perlu dioptimalkan untuk memperoleh jumlah produksi yang maksimal. Jarak antar pelampung dalam metode tali panjang untuk budidaya rumput laut $K$. alvarezii di perairan Kabupaten Gorontalo telah diteliti oleh Pong-Masak \& Pantjara (2009). Beberapa faktor pengelolaan dalam budidaya rumput laut di perairan pantai Selatan Sulawesi Selatan juga telah dilaporkan oleh Ratnawati et al. (2010).
Penelitian ini dilakukan untuk mengetahui upaya peningkatan produktivitas rumput laut dengan memperhatikan faktor-faktor pengelolaan yang berpengaruh terhadap rumput laut $K$. alvarezii yang dilakukan oleh pembudidaya rumput laut di Kabupaten Konawe Selatan Provinsi Sulawesi Tenggara.

\section{BAHAN DAN METODE}

Penelitian dilakukan pada bulan Maret 2012 di Kecamatan Tinanggea, Lainea, Palangga Selatan, dan Laiya Kabupaten Konawe Selatan Provinsi Sulawesi Tenggara. Untuk mendapatkan informasi awal dilakukan pertemuan dengan staf Dinas Kelautan dan Perikanan Kabupaten Konawe Selatan di Andoolo mengenai kegiatan budidaya rumput laut $K$. alvarezii dan memilih responden pembudidaya rumput laut $K$. alvarezii secara acak.

Data primer dari produksi dan pengelolaan yang dilakukan oleh pembudidaya rumput laut diperoleh dengan menggunakan metode survai, dengan tujuan untuk membuat deskripsi komprehensif dalam menjelaskan hubungan antar berbagai peubah yang diteliti (Ali, 2010). Metode survai dilakukan dengan mengajukan beberapa pertanyaan kepada responden secara terstruktur (Wirartha, 2006). Daftar pertanyaan yang digunakan telah diuji terlebih dahulu pada responden. Data primer dari pengelolaan budidaya diketahui melalui pengamatan dan pengukuran langsung di lapangan. Kondisi umum lokasi budidaya rumput laut $K$. alvarezii yang diukur meliputi salinitas dengan refraktometer, kecerahan perairan dengan piring secchi, kedalaman perairan dengan tali berskala yang dilengkapi pemberat, dan substrat dasar diambil dengan menggunakan grab sampler. Sebagai peubah tidak bebas dalam penelitian ini adalah produksi rumput laut $K$. alvarezii. Produksi rumput laut $K$. alvarezii dinyatakan dalam kilogram kering/3.000 $\mathrm{m}^{2}$. Penentuan $3.000 \mathrm{~m}^{2}$ didasarkan pada rata-rata panjang tali ris dan 
jumlah tali ris yang dipasang oleh pembudidaya. Peubah bebas dalam penelitian ini adalah pengelolaan budidaya rumput laut $K$. alvarezii. Posisi lokasi budidaya rumput laut ditentukan dengan menggunakan GPS (Global Positioning System).

Gambaran umum dari data yang diperoleh dianalisis secara statistik deskriptif yaitu minimum, maksimum, rata-rata, dan deviasi standar. Matriks korelasi digunakan untuk mengetahui adanya gejala multikolineritas. Grafik plot PP (Probabilitas harapan dan Probabilitas pengamatan) digunakan untuk menguji kenormalan distribusi data. Scatterplot regresi digunakan untuk mengetahui adanya gejala heteroskedastisitas. Uji DW (DurbinWatson) digunakan untuk mendeteksi adanya gejala autokorelasi. Dalam memilih persamaan regresi ganda 'terbaik' maka digunakan metode langkah mundur (backward) (Draper \& Smith, 1981). Analisis regresi berganda diaplikasikan untuk mengetahui peubah bebas yang memengaruhi peubah tidak bebas.

Koefisien determinasi $\left(R^{2}\right)$ yang disesuaikan (adjusted $\mathrm{R}^{2}$ ) digunakan untuk mengetahui seberapa baik garis regresi sesuai dengan data aktualnya (goodness of fit). Koefisien determinasi mengukur persentase total variasi peubah tidak bebas $Y$ yang dijelaskan oleh peubah bebas $X$. Uji F atau analisis ragam digunakan untuk menguji signifikansi model regresi. Model persamaan regresi berganda yang diuji adalah (Sokal \& Rohlf, 1981; Tabachnick \& Fidell, 1996):

$Y=a+b_{1} X_{1}+b_{2} X_{2}+\ldots+b_{n} X_{n} \quad$ (Persamaan 1)

di mana:

$\mathrm{Y}=$ Produksi rumput laut $K$. alvarezii (Seaweed production)

$\mathrm{a}=$ Koefisien konstanta (Constanta coefficient)

$\mathrm{b}_{1}, \mathrm{~b}_{2}, \ldots \mathrm{b}_{\mathrm{n}}=$ Koefisien regresi (Regression coefficient)

$\mathrm{X}_{1}, \mathrm{X}_{2}, \ldots \mathrm{X}_{\mathrm{n}}=$ Peubah bebas yaitu pengelolaan budidaya rumput laut $K$. alvarezii (Independent variable which was seaweed culture management factors)

Seluruh data dianalisis dengan bantuan Program Statistical Product and Service Solution (SPSS) versi 1 5,0 (Coakes et al., 2008).

\section{HASIL DAN BAHASAN}

Pembudidaya rumput laut Kecamatan Tinanggea, Lainea, Palangga Selatan, dan Laiya di Kabupaten Konawe Selatan menggunakan metode tali panjang (long line). Metode long line paling banyak diminati karena fleksibel dalam pemilihan lokasi, biaya dan ongkos material relatif lebih murah, dan memiliki keuntungan dapat terhindar dari hama bulu babi, serta memiliki pertumbuhan lebih cepat (Anggadiredja et al., 2006).

K. alvarezii merupakan rumput laut yang relatif tidak tahan terhadap kisaran salinitas yang luas. Salinitas yang sesuai untuk pertumbuhannya adalah berkisar 28-35 ppt. Penurunan salinitas akibat masuknya air tawar akan menyebabkan pertumbuhan menjadi tidak normal. Untuk memperoleh perairan dengan kondisi salinitas tersebut harus dihindari lokasi yang berdekatan dengan muara sungai. Budidaya rumput laut K. alvarezii di Kabupaten Konawe Selatan, dilakukan pada perairan dengan salinitas antara 28-33 ppt (Tabel 1). Hasil pengukuran salinitas di perairan tersebut menunjukkan salinitas pertumbuhan yang baik untuk budidaya rumput laut. Salinitas untuk pertumbuhan rumput laut $K$. alvarezii berkisar antara 27-34 ppt (Sadhori, 1989) dan 28-33 ppt (Anggadiredja et al., 2006).

Kecerahan perairan di lokasi budidaya rumput laut berkisar antara 0,6 m dan 15,0 m. Beberapa lokasi ditemukan dengan tingkat kecerahan yang rendah karena substrat berupa lumpur dan dekat dengan muara sungai. Substrat perairan yang jernih dengan tingkat kecerahan yang tinggi sekitar 2-5 m dan didominasi oleh pecahan-pecahan karang dan pasir kasar merupakan substrat perairan yang sesuai untuk budidaya rumput laut. Air keruh yang mengandung lumpur dapat menghalangi cahaya matahari ke dalam air, serta dapat menutupi permukaan talus yang dapat menyebabkan talus membusuk sehingga mudah patah. Rumput laut $K$. alvarezii dapat hidup pada kedalaman di mana cahaya matahari masih ada, hal ini dikatakan berada pada lapisan fotik. Kedalaman air pada saat surut terendah minimal 0,4 m (Anggadiredja et al., 2006) dan 0,6 m (Aslan, 1998) sampai kedalaman di mana cahaya matahari masih dapat mencapai rumput laut $K$. alvarezii dan pembudidaya masih mampu melakukan kegiatan budidaya merupakan lokasi yang cocok untuk budidaya rumput laut $K$. alvarezii.

K. alvarezii tumbuh melekat ke substrat dengan alat perekat berupa cakram. Cabangcabang pertama dan kedua tumbuh dengan membentuk rumpun yang rimbun dengan ciri khusus mengarah ke arah datangnya sinar 
Tabel 1. Kondisi perairan dan substrat budidaya rumput laut Kappaphycus alvarezii di Kabupaten Konawe Selatan Provinsi Sulawesi Tenggara

Table 1. Condition of waters and substrate waters and suitable condition of Kappaphycus alvarezii seaweed culture in South Konawe District, Southeast Sulawesi Province

\begin{tabular}{|c|c|c|c|c|c|}
\hline $\begin{array}{l}\text { Peubah } \\
\text { Variables }\end{array}$ & $\begin{array}{c}\text { Minimum } \\
\text { Minimum }\end{array}$ & $\begin{array}{l}\text { Maksimum } \\
\text { Maximum }\end{array}$ & $\begin{array}{l}\text { Kisaran } \\
\text { Range }\end{array}$ & $\begin{array}{l}\text { Rataan } \\
\text { Average }\end{array}$ & $\begin{array}{c}\text { Standar deviasi } \\
\text { Standard } \\
\text { deviation }\end{array}$ \\
\hline $\begin{array}{l}\text { Salinitas } \\
\text { Salinity (ppt) }\end{array}$ & 28.25 & 32.9 & 10.65 & 31.93 & 1.261 \\
\hline $\begin{array}{l}\text { Kecerahan } \\
\text { Transparancy }(\mathrm{m})\end{array}$ & 0.6 & 15.0 & 14.4 & 6.34 & 4.456 \\
\hline Kedalaman $($ Depth $)(\mathrm{m})$ & 1 & 42.5 & 41.5 & 13.26 & 10.462 \\
\hline Substrat (Substrate) & \multicolumn{5}{|c|}{$\begin{array}{l}\text { Lumpur }(\text { Mud })=57.14 \%, \text { Lumpur berpasir }(\text { Sandy } \text { mud })=5.71 \% \text {, } \\
\text { Pasir berlumpur }(\text { Muddy sand })=10.00 \% \text {, Pasir }(\text { Sand })=12.86 \% \text {, } \\
\text { Pasir berke rikil }(\text { Pebbly sand })=1.43 \%, \text { Karang }(\text { Coral })=7.32 \% \text {, } \\
\text { Batu karang }(\text { Reef })=1.25 \%, \text { Karang hidup }(\text { Live coral })=2.86 \% \text {, } \\
\text { Pasir berkarang (Rocky sand })=1.43 \%\end{array}$} \\
\hline
\end{tabular}

matahari (Atmadja et al., 1996). Umumnya $K$. alvarezii tumbuh dengan baik di daerah pantai berkarang. Habitat khasnya adalah daerah yang memperoleh aliran air laut. Substrat dasar perairan di lokasi budidaya rumput laut di Kabupaten Konawe didominasi oleh lumpur. Menurut Aslan (1998), substrat dasar yang ideal untuk rumput laut $K$. alvarezii adalah karang yang terdiri atas pasir kasar yang bercampur dengan potongan-potongan karang. Rumput laut $K$. alvarezii yang dipelihara pada perairan dengan substrat karang mempunyai ukuran diameter talus yang lebih besar yaitu $0,95 \mathrm{~cm}$ dan bercabang banyak namun percabangannya agak pendek, sedangkan yang tumbuh pada perairan dengan substrat dasar pasir mempunyai talus $0,55 \mathrm{~cm}$ dan bercabang kurang namun percabangannya agak panjang (Patadjai, 2007).

Identifikasi terhadap pembudidaya rumput laut $K$. alvarezii di perairan Kabupaten Konawe Selatan Provinsi Sulawesi Tenggara, dari 24 peubah pengelolaan yang dianalisis dengan korelasi Pearson, hanya ada 14 peubah yang memiliki gejala multikolineritas, sehingga hanya ada 14 peubah pengelolaan budidaya yang dipilih untuk analisis lebih lanjut. Peubah yang dipilih merupakan peubah pengelolaan yang lebih mudah diukur. Hasil analisis menunjukkan bahwa tidak ada gejala heteroskedastisitas dan data terdistribusi normal.
Penentuan model didasarkan pada galat estimasi standar (standard error of estimate) karena nilai $\mathrm{R}^{2}$ yang disesuaikan (adjusted $\mathrm{R}^{2}$ ) pada Lampiran 1 diperoleh adalah 0,633 didapat pada model 1. Selain itu, karena galat estimasi standar lebih kecil dari deviasi standar produksi rumput laut yang besarnya $425 \mathrm{~kg}$ kering/3.000 $\mathrm{m}^{2}$ (Tabel 2), maka model regresi lebih baik dalam bertindak sebagai model untuk memprediksi produksi rumput laut $K$. alvarezii daripada rata-rata produksi rumput laut $K$. alvarezii itu sendiri. Berdasarkan hasil analisis ragam (Lampiran 2) menunjukkan model 1 dapat digunakan untuk memprediksi produksi rumput laut $K$. alvarezii di perairan Kabupaten Konawe Selatan $(P=0,000)$.

Karena $\mathrm{R}^{2}$ yang diperoleh adalah 0,633 ; menunjukkan bahwa $63,3 \%$ produksi rumput laut $K$. alvarezii dapat dijelaskan oleh peubah pengelolaan budidaya rumput laut $K$. alvarezii yang meliputi jumlah tali ris (per $3.000 \mathrm{~m}^{2}$ ), umur bibit rumput laut dipanen (hari), jarak antar rumpun dalam tali ris (cm), dan pengontrolan rumput laut (kali/minggu), serta sisanya $(36,7 \%)$ merupakan faktor lain yang tidak diamati dalam penelitian ini.

Untuk memprediksi produksi rumput laut K. alvarezii di perairan Kabupaten Konawe Selatan Provinsi Sulawesi Tenggara, digunakan hasil analisis dengan nilai koefisien konstanta dan koefisien regresi dari persamaan 
Tabel 2. Statistik deskriptif dari berbagai peubah pengelolaan budidaya dan produksi rumput laut Kappaphycus alvarezii di Kabupaten Konawe Selatan Provinsi Sulawesi Tenggara $(\mathrm{n}=27)$

Table 2. Descriptive statistics of various variables culture and production management seaweed Kappaphycus alvarezii in South Konawe District Southeast Sulawesi Province $(n=27)$

\begin{tabular}{|c|c|c|c|c|c|}
\hline $\begin{array}{l}\text { Peubah } \\
\text { Variables }\end{array}$ & $\begin{array}{l}\text { Minimum } \\
\text { Minimum }\end{array}$ & $\begin{array}{l}\text { Maksimum } \\
\text { Maximum }\end{array}$ & $\begin{array}{l}\text { Kisaran } \\
\text { Range }\end{array}$ & $\begin{array}{l}\text { Rataan } \\
\text { Average }\end{array}$ & $\begin{array}{l}\text { Standar } \\
\text { deviasi } \\
\text { Standard } \\
\text { deviation }\end{array}$ \\
\hline $\begin{array}{l}\text { Produksi rumput laut (bobot kering } \\
\left.\mathrm{kg} / 3,000 \mathrm{~m}^{2}\right)(\text { Seaweed production } \\
\left.\left(\mathrm{kg} \text { dry weight } / 3,000 \mathrm{~m}^{2}\right)\right)\end{array}$ & 540 & 2,160 & 1,620 & 942.3 & 424.64 \\
\hline $\begin{array}{l}\text { Total tali ris yang dimiliki (buah) } \\
\text { Total of long line held (pieces) }\end{array}$ & 90 & 500 & 410 & 224.1 & 130.13 \\
\hline $\begin{array}{l}\text { Total tali ris yang dipasang (buah) } \\
\text { Total long line set (pieces) }\end{array}$ & 70 & 500 & 430 & 207.4 & 135.46 \\
\hline $\begin{array}{l}\text { Jumlah tali ris (buah/300 m²)) } \\
\text { Number of long line (pieces } / 300 \mathrm{~m}^{2} \text { ) }\end{array}$ & 40 & 120 & 80 & 60.3 & 14.89 \\
\hline $\begin{array}{l}\text { Panjang tali ris } \\
\text { Length of long line }(\mathrm{m})\end{array}$ & 25 & 75 & 50 & 52.0 & 10.76 \\
\hline $\begin{array}{l}\text { Jarak antar tali ris } \\
\text { Distance of long line (m) }\end{array}$ & 100 & 100 & 0 & 100.0 & 0.00 \\
\hline $\begin{array}{l}\text { Jarak antar rumpun dalam tali ris } \\
\text { Distance clump in long line }(\mathrm{cm})\end{array}$ & 7 & 20 & 13 & 9.3 & 4.13 \\
\hline $\begin{array}{l}\text { Jumlah unit budidaya } \\
\text { Number of culture unit (unit) }\end{array}$ & 1 & 7 & 6 & 2.7 & 1.44 \\
\hline $\begin{array}{l}\text { Kedalaman tali bentang } \\
\text { Depth of long line }(\mathrm{cm})\end{array}$ & 10 & 50 & 40 & 22.8 & 13.47 \\
\hline $\begin{array}{l}\text { Bobot bibit (g/ikat) } \\
\text { Seed weight (g/rope) }\end{array}$ & 11 & 120 & 108.8 & 28.1 & 25.72 \\
\hline $\begin{array}{l}\text { Pengontrolan rumput laut (kali/minggu) } \\
\text { Seaweed control (time/weeks) }\end{array}$ & 1 & 7 & 6 & 2.9 & 2.14 \\
\hline $\begin{array}{l}\text { Umur dipanen (hari) } \\
\text { Harvest time (days) }\end{array}$ & 30 & 60 & 30 & 43.3 & 5.3 \\
\hline $\begin{array}{l}\text { Lama pengeringan (hari) } \\
\text { Duration of dry (days) }\end{array}$ & 3 & 3 & 0 & 3.0 & 0.00 \\
\hline $\begin{array}{l}\text { Umur bibit dipanen (hari) } \\
\text { Harvest time of seed (days) }\end{array}$ & 21 & 45 & 24 & 31.2 & 9.41 \\
\hline
\end{tabular}

regresi (Lampiran 3) dengan persamaan regresi sebagai berikut:

$Y=831.673+8.865 X_{1}-20.168 X_{2}+11.667 X_{3}$ $+33.308 \mathrm{X}_{4}$

(Persamaan 2)

di mana:

$\mathrm{Y}=$ Produksi rumput laut kering $\left(\mathrm{kg} / 3.000 \mathrm{~m}^{2}\right)$
$\mathrm{X}_{1}=$ Jumlah tali ris (per $3.000 \mathrm{~m}^{2}$ )

$\mathrm{X}_{2}=$ Umur bibit rumput laut dipanen (hari)

$\mathrm{X}_{3}=$ Jarak antar rumpun dalam tali ris $(\mathrm{cm})$

$\mathrm{X}_{4}=$ Pengontrolan rumput laut (kali/minggu)

Hasil analisis peubah faktor pengelolaan budidaya diperoleh empat peubah yang berpengaruh dari 14 peubah yang dikaji dalam 
penelitian ini yaitu: jumlah tali ris, umur rumput laut bibit dipanen, jarak antar rumpun dalam tali ris, dan pengontrolan rumput laut (Persamaan 2) yang merupakan peubah pengelolaan budidaya yang berpengaruh secara nyata dalam menentukan produksi rumput laut K. alvarezii. Dari Persamaan 2, terlihat bahwa koefisien konstanta sebesar 831.673 yang berarti produksi rumput laut $K$. alvarezii dapat diprediksi mencapai $831.673 \mathrm{~kg}$ kering/3.000 $\mathrm{m}^{2}$ kalau tidak ada kontribusi dari peubah pengelolaan budidaya. Hal ini menunjukkan bahwa peubah pengelolaan budidaya yang meliputi: jumlah tali ris, umur rumput laut bibit dipanen, jarak antar rumpun dalam tali ris, dan pengontrolan rumput laut berpengaruh besar terhadap produksi rumput laut $K$. alvarezii.

Koefisien regresi dari jumlah tali ris per $3.000 \mathrm{~m}^{2}\left(\mathrm{X}_{1}\right)$ sebesar 8.865 menunjukkan bahwa setiap penambahan jumlah tali ris sebesar $120 \mathrm{~m} / 3.000 \mathrm{~m}^{2}$, akan meningkatkan produksi rumput laut sebesar $8.865 \mathrm{~kg}$ kering/ $3.000 \mathrm{~m}^{2}$. Hal tersebut dapat dimengerti bahwa makin banyak jumlah tali ris berarti jumlah penanaman makin bertambah sehingga akan meningkatkan produksi rumput laut. Penambahan jumlah tali ris harus memperhatikan beberapa faktor penting yang menentukan keberhasilan usaha budidaya, meliputi: ketersediaan bibit, arus, kondisi dasar perairan, kedalaman, salinitas, kecerahan, pencemaran, dan tenaga kerja. Rumput laut merupakan organisme yang memperoleh makanan melalui aliran air yang melewatinya atau melalui sintesis bahan makanan di sekitarnya dengan bantuan cahaya matahari, dengan memperhatikan aliran air yang cukup, akan dapat menghindari terkumpulnya kotoran pada talus, membantu pengudaraan, dan mencegah adanya fluktuasi yang besar terhadap salinitas maupun suhu air.

Dari persamaan terlihat bahwa umur rumput laut bibit dipanen $\left(\mathrm{X}_{2}\right)$ dapat menurunkan jumlah produksi sebesar $831.673 \mathrm{~kg} / 3.000 \mathrm{~m}^{2}$. Keberhasilan suatu usaha budidaya sangat tergantung pada bibit yang disediakan. Bibit rumput laut dapat berasal dari stok alam atau dari hasil budidaya. Keuntungan bila bibit berasal dari alam adalah di samping mudah pengadaannya juga cocok dengan persyaratan pertumbuhan secara alami. Sedangkan kerugiannya bibit sering tercampur dengan jenis rumput laut lain. Bibit yang berasal dari hasil budidaya lebih murni karena hanya terdiri atas satu jenis rumput laut (Indriani \&
Sumiarsih, 1991). Menurut Setiadi \& Budiharjo (2000), pemilihan bibit dalam budidaya rumput laut adalah sebagai berikut:

a) Bibit berupa stek dipilih dari tanaman yang segar, dapat diambil dari tanaman yang tumbuh secara alami ataupun dari tanaman bekas budidaya. Selain itu, bibit masih baru dan masih muda.

b) Bibit unggul mempunyai ciri bercabang banyak (rimbun), elastis, dan bebas dari penyakit.

c) Bibit sebaiknya dikumpulkan dari perairan pantai sekitar lokasi usaha budidaya dalam jumlah yang sesuai dengan luas area budidaya.

d) Sewaktu disimpan harus diperhatikan seksama dengan menghindari dari kekeringan.

Penentuan umur panen merupakan hal penting untuk dapat menghasilkan kualitas rumput laut tidak hanya dipengaruhi oleh teknik atau metode budidayanya saja. Panen dapat dibedakan berdasarkan tujuannya yaitu untuk bibit dan untuk produksi. Panen untuk bibit dilakukan pada saat rumput laut berumur 25-35 hari dengan memperhatikan persyaratan bibit yang berkualitas baik, sedangkan panen untuk produksi dilakukan pada umur 45 hari agar kandungan karagenannya bernilai optimum (DJPB, 2004). Secara umum kandungan dan komposisi kimia rumput laut dipengaruhi oleh jenis rumput laut, fase (tingkat pertumbuhan), dan umur panennya.

Dari hal tersebut dapat diketahui bahwa umur rumput laut bibit yang dipanen harus memenuhi kriteria bibit yang baik agar menghasilkan produksi rumput laut sesuai harapan pembudidaya. Umur rumput laut bibit yang dipanen oleh pembudidaya rumput laut di Kabupaten Konawe Selatan rata-rata 31 hari. Anggadiredja et al. (2006) mengatakan bahwa kriteria bibit rumput laut yang baik adalah talus muda dan bercabang banyak, sehat dan tidak terdapat bercak, luka atau terkelupas, terlihat segar dan berwarna cerah yaitu cokelat cerah atau hijau cerah, bibit harus seragam dan tidak boleh bercampur dengan jenis lain, bobot bibit awal sekitar $100 \mathrm{~g} /$ ikatan atau rumpun. Bibit unggul yang baik adalah memiliki kemampuan adaptasi tinggi terhadap fluktuasi lingkungan perairan dan kemampuan tumbuh di atas $10 \%$ dalam periode pembudidayaan selama satu bulan (Nurdjana, 2006). Bibit yang digunakan pada pembudidaya rumput laut di Kabupaten Konawe 
Selatan rata-rata diperoleh dari hasil budidaya sendiri dan dari pembudidaya lain dalam desa yang berbeda, sehingga hal ini merupakan salah satu kendala dalam keberhasilan budidaya rumput laut, yaitu adanya ketersediaan benih yang memadai, berkualitas, dan berkesinambungan.

Jarak antar rumpun dalam tali ris $\left(\mathrm{X}_{3}\right)$ sebesar 11.667 yang berarti setiap peningkatan jarak antar rumpun dalam tali ris sebesar $1 \mathrm{~cm}$ dapat meningkatkan produksi rumput laut sebesar $11.667 \mathrm{~kg}$ kering $/ 3.000 \mathrm{~m}^{2}$. Jarak antar rumpun dalam tali ris yang diaplikasikan oleh pembudidaya rumput laut $K$. alvarezii di perairan Kabupaten Konawe Selatan berkisar antara 7-20 cm (Tabel 2). Penambahan jarak antar rumpun dalam tali ris akan memengaruhi perkembangan pertumbuhan rumput laut, karena semakin jauh jarak tanam akan semakin luas lalu lintas pergerakan air dan juga akan menghindari terkumpulnya kotoran pada talus, serta membawa unsur hara sehingga pertumbuhan rumput laut meningkat (Afrianto \& Leviawati, 1989). Jarak antar rumpun dalam tali ris yang dilakukan oleh pembudidaya rumput laut di Kabupaten Konawe Selatan yaitu minimal $7 \mathrm{~cm}$ dan maksimal 20 $\mathrm{cm}$. Untuk efisiensi pemanfaatan lahan budidaya, jarak antar rumpun dalam tali ris sebaiknya maksimal $30 \mathrm{~cm}$, agar dapat meningkatkan produksi rumput laut K. alvarezii. Beberapa penelitian yang telah dilakukan pada metode tali panjang, bibit rumput laut $K$. alvarezii diikat pada tali ris dengan jarak $20 \mathrm{~cm}$ (Afrianto \& Liviawaty, 1989), $25 \mathrm{~cm}$ (Anggadiredja et al., 2006), $30 \mathrm{~cm}$ (Patadjai, 2007) dan antara 10 sampai $15 \mathrm{~cm}$ (Pantjara et al., 2010).

Memelihara rumput laut berarti memantau dan merawat terus-menerus konstruksi budidaya dan tanamannya. Pemeliharaan dilakukan pada saat ombak besar maupun saat laut tenang. Kerusakan patok, jangkar, tali ris, dan tali ris utama disebabkan oleh ombak yang besar. Kotoran yang melekat pada tanaman dapat mengganggu proses metabolisme sehingga laju pertumbuhan menurun. Beberapa tumbuhan penempel seperti Ulva, Hypnea, Chaetomorpha, dan Enteromorpha sering membelit tanaman dan konstruksi budidaya sehingga dapat menimbulkan kerusakan (Indriani \& Sumiarsih, 1991). Menurut Setiadi \& Budihardjo (2000), hal-hal yang perlu diperhatikan selama pemeliharaan rumput laut yaitu, pembersihan tanaman dari tumbuhan penempel atau tanaman lainnya. Tanaman yang hilang atau rusak karena terserang hama atau arus air yang kuat diganti dengan tanaman yang baru. Selain itu, dilakukan pula pemantauan kualitas air, monitoring pertumbuhan, dan perbaikan sarana budidaya. Koefisien regresi untuk pengontrolan rumput laut $\left(\mathrm{X}_{4}\right)$ yang dilakukan oleh pembudidaya rumput laut di Kabupaten Konawe Selata pada Persamaan 2 adalah 33.308 yang berarti bahwa pengontrolan rumput laut dapat meningkatkan hasil produksi sebesar 33.308 $\mathrm{kg} / 3.000 \mathrm{~m}^{2}$. Hal tersebut jelas sangat berpengaruh terhadap hasil produksi karena dengan adanya pengontrolan rumput laut yang dilakukan secara rutin, hal-hal yang dapat memengaruhi pertumbuhan rumput laut dapat diatasi oleh pembudidaya.

\section{KESIMPULAN DAN SARAN}

Produksi rumput laut Kappaphycus alvarezii di Konawe Selatan, berkisar antara $540-2.160 \mathrm{~kg} / 3.000 \mathrm{~m}^{2}$ dengan rata-rata $942 \mathrm{~kg}$ kering/3.000 $\mathrm{m}^{2}$ yang dibudidayakan dengan metode tali panjang. Faktor pengelolaan budidaya yang memengaruhi produksi rumput laut adalah jumlah tali ris, umur bibit rumput laut dipanen, jarak antar rumpun dalam tali ris, dan pengontrolan rumput laut. Untuk meningkatkan produksi rumput laut di perairan Konawe Selatan dapat dilakukan melalui penambahan jumlah tali ris dengan memperhatikan ketersediaan bibit, arus, kondisi dasar perairan, kedalaman, salinitas, kecerahan, pencemaran, dan tenaga kerja. Umur bibit rumput laut yang berkualitas baik harus diperhatikan dengan melakukan panen bibit pada saat umur 25-35 hari, penambahan jarak antar rumpun dalam tali ris maksimal $30 \mathrm{~cm}$ dan pengontrolan rumput laut harus rutin dilakukan agar dapat meminimalkan masalah selama budidaya.

\section{DAFTAR ACUAN}

Afrianto, E., \& Liviawaty, E. (1989). Budidaya laut dan cara pengolahannya. Bharata. Jakarta, hlm. 60-64.

Ali, M. (2010). Metodologi dan aplikasi riset pendidikan. Pustaka Cendikia Utama. Bandung, $392 \mathrm{hlm}$.

Anggadiredja, J.T., Zatmika, A., Purwoto, H., \& Istini, S. (2006). Rumput laut: pembudidayaan, pengolahan \& pemasaran komoditas perikanan potensial. Penerbit Penebar Swadaya. Jakarta, $147 \mathrm{hlm}$. 
Aslan, L.M. (1998). Budidaya Rumput laut. Penerbit Kanisius. Yogyakarta, $105 \mathrm{hlm}$.

Atmadja, W.S. (1990). Rumput Laut Sebagai Obat. Jurnal Oseana, 17, 1-8.

Atmadja, W.S., Kadi, A., Sulistijo, \& Satari, R. (1996). Pengenalan jenis-jenis rumput laut Indonesia. Puslitbang Oseanologi LIPI. Jakarta.

Coakes, S.J., Steed, L., \& Price, J. (2008). SPSS: Analysis without anguish: Version 15.0 for Windows. John Wiley \& Sons Australia, Ltd., Milton, Qld, 270 pp.

Direktorat Jenderal Perikanan Budidaya (DJPB). (2004a). Pedoman umum budidaya rumput laut di laut. Kementerian Kelautan dan Perikanan. Jakarta.

Draper, N.R., \& Smith, H. (1981). Applied regression analiysis. Second edition. John Wiley \& Sons. New York, 709 pp.

Indriani, \& Sumiarsih. (1991). Budidaya, pengolahan dan pemasaran rumput laut. Penebar Swadaya. Jakarta, $79 \mathrm{hlm}$.

Kurniawan, A. (2011). Serba-serbi analisis statistika dengan cepat dan mudah. Jasakom. Jakarta, $136 \mathrm{hlm}$.

Nurdjana, M.L. (2006). Pengembangan budidaya rumput laut di Indonesia, hlm. 1-35. Dalam Handout Diseminasi Teknologi dan Temu Bisnis Rumput Laut. Badan Riset Kelautan dan Perikanan. Jakarta,

Parenrengi, A., Rachmansyah, \& Suryati, E. (2010). Budidaya rumput laut penghasil karaginan (karaginofit). Balai Riset Perikanan Budidaya Air Payau, Badan Penelitian dan Pengembangan Kelautan Perikanan, Kementerian Kelautan dan Perikanan. Jakarta, $54 \mathrm{hlm}$.

Patadjai, R.S. (2007). Pertumbuhan, produksi dan kualitas rumput laut Kappaphycus alvarezii (Doty) pada berbagai habitat budidaya yang berbeda. Disertasi. Program Pascasarjana, Universitas Hasanuddin. Makassar, $163 \mathrm{hlm}$.

Pantjara, B., Pong-Masak, P.R., \& Hetiningrum, S.R. (2010). Kondisi perairan dan kandungan karaginan rumput laut Kappaphycus alvarezii dan Eucheuma denticulatum di Perairan Gorontalo Utara. Prosiding Seminar Nasional Rumput Laut dan Minisimposium Mikroalga II. Ikatan Fikologi Indonesia. Jakarta, hlm. 12-23.

Pong-Masak, P.R., \& Pantjara, B. (2009). Optimasi jarak botol pelampung tali bentangan pada budidaya rumput laut metode long line di perairan Gorontalo Utara. Dalam Buku Panduan Seminar Nasional Perikanan 2009. Sekolah Tinggi Perikanan. Jakarta, 1 $\mathrm{hlm}$.

Ratnawati, E., Mustafa, A., \& Daud, R. (2010). Faktor pengelolaan yang memengaruhi tingkat produksi rumput laut Kappaphycus alvarezii di perairan pantai Selatan Provinsi Sulawesi Selatan. J. Ris. Akuakultur, 5(3), 491-504.

Sadhori, S.N. (1989). Budidaya rumput laut. Balai Pustaka. Jakarta, $109 \mathrm{hlm}$.

Setiadi, A., \& Budihardjo, U. (2000). Rumput laut komoditas unggulan. Grasindo. Jakarta, hlm. 33-35.

Sokal, R.R., \& Rohlf, F.J. (1981). Biometry: The principles and practice of statistics in biological research. Second edition: W.H. Freeman and Co. New York, 859 pp.

Tabachnick, B.G., \& Fidell, L.S. (1996). Using multivariate statistics. Third edition. Harper Collins College Publishers. New York, 880 pp.

Wirartha, I M. (2006). Metodologi penelitian sosial ekonomi. Penerbit Andi. Yogyakarta, $383 \mathrm{hlm}$. 
Lampiran 1. Ringkasan model untuk menentukan faktor pengelolaan budidaya yang memengaruhi produksi rumput laut Kappaphycus alvarezii di Kabupaten Konawe Selatan Provinsi Sulawesi Tenggara

Appendix 1. Summary model for determining factors affecting production management aquaculture seaweed Kappaphycus alvarezii in South Konawe District South-East Sulawesi Province

\begin{tabular}{cccccc}
\hline $\begin{array}{c}\text { Model } \\
\text { Model }\end{array}$ & $\mathbf{R}$ & $\mathbf{R}^{2}$ & $\begin{array}{c}\mathbf{R}^{2} \text { yang } \\
\text { disesuaikan } \\
\text { Adjusted } \mathbf{R}^{2}\end{array}$ & $\begin{array}{c}\text { Kesalahan } \\
\text { estimasi standar } \\
\text { Standard error } \\
\text { of } \boldsymbol{t h e} \text { estimate }\end{array}$ & $\begin{array}{c}\text { Durbin- } \\
\text { Watson }\end{array}$ \\
\hline 1 & $.633^{\mathrm{a}}$ & .401 & .292 & 357.35370 & 1.752 \\
\hline
\end{tabular}

Keterangan (Note):

a. Predictors: (Constant), Pengontrolan rumput laut (kali/minggu) (Seaweed control (time/weeks)), Jarak antar rumpun dalam tali ris (Distance clump in long line) $(\mathrm{cm})$, Jumlah tali ris (buah/3.000 $\mathrm{m}^{2}$ ) (Number of long line (pieces $\left./ 3,000 \mathrm{~m}^{2}\right)$ ), Umur bibit rumput laut dipanen (hari) (Harvest time of seed (days))

b. Variabel dependen (Dependent variable) : Produksi rumput laut (Seaweed production) $(\mathrm{kg} /$ $3.000 \mathrm{~m}^{2}$ ) 
Lampiran 2. Analisis ragam dari faktor pengelolaan budidaya yang memengaruhi produksi rumput laut Kappaphycus alvarezii di Kabupaten Konawe Selatan Provinsi Sulawesi Tenggara

Appendix 2. Variety analysis of factors affecting the production management aquaculture seaweed Kappaphycus alvarezii in South Konawe District South-East Sulawesi Province

\begin{tabular}{llccccc}
\hline & Model & Sum of squares & df & Mean square & F & Sig. \\
\hline \multirow{2}{*}{1} & Regresi(Regression) & 1878754.399 & 4 & 469688.600 & 3.678 & $.019^{b}$ \\
& Residual & 2809436.690 & 22 & 127701.668 & & \\
\hline & Jumlah (Total) & 4688191.089 & 26 & & & \\
\hline
\end{tabular}

Keterangan (Note):

a. Variabel dependen (Dependent variable) : Produksi rumput laut (Seaweed production) $\left(\mathrm{kg} / 3.000 \mathrm{~m}^{2}\right)$

b. Predictors: (Constant), Pengontrolan rumput laut (kali/minggu) (Seaweed control (time/weeks)), Jarak antar rumpun dalam tali ris (Distance clump in long line) $(\mathrm{cm})$, Jumlah tali ris (buah/3.000 $\left.\mathrm{m}^{2}\right)($ Number of long line (pieces $\left./ 3,000 \mathrm{~m}^{2}\right)$ ), Umur bibit rumput laut dipanen (hari) (Harvest time of seed (days)) 
Lampiran 3. Konstanta dan koefisien regresi pada model 1 dari faktor pengelolaan budidaya yang memengaruhi produksi rumput laut Kappaphycus alvarezii di Kabupaten Konawe Selatan Provinsi Sulawesi Tenggara

Appendix 3. Constants and regression coefficients of the model 1 of factors affecting the production management of aquaculture seaweed Kappaphycus alvarezii in South Konawe District South-East Sulawesi Province

\begin{tabular}{|c|c|c|c|c|c|c|}
\hline & \multirow[t]{2}{*}{ Model } & \multicolumn{2}{|c|}{$\begin{array}{l}\text { Koefisen tidak } \\
\text { st andar } \\
\text { Unstandardized } \\
\text { Coefficients }\end{array}$} & \multirow{2}{*}{$\begin{array}{c}\begin{array}{c}\text { Koefisien } \\
\text { standar } \\
\text { Standardized } \\
\text { coefficients }\end{array} \\
\text { Beta }\end{array}$} & \multirow[t]{2}{*}{$\mathbf{t}$} & \multirow[t]{2}{*}{ Sig. } \\
\hline & & B & Std. Error & & & \\
\hline \multirow{5}{*}{1} & Constant & 831.673 & 395.710 & & 2.102 & .047 \\
\hline & $\begin{array}{l}\text { Jumlah tali ris (buah/3.000 } \mathrm{m}^{2} \text { ) } \\
\text { Number of long line (pieces/ } \\
3,000 \mathrm{~m}^{2} \text { ) }\end{array}$ & 8.865 & 5.139 & .311 & 1.725 & .099 \\
\hline & $\begin{array}{l}\text { Umur bibit rumput laut dipanen } \\
\text { (hari) }(\text { Harvest time of seed } \\
(\text { days }))\end{array}$ & -20.168 & 8.927 & -.447 & -2.259 & .034 \\
\hline & $\begin{array}{l}\text { Jarak antar rumpun dalam tali ris } \\
\text { Distance clump in long line }(\mathrm{cm})\end{array}$ & 11.667 & 18.832 & .113 & .620 & .542 \\
\hline & $\begin{array}{l}\text { Pengontrolan rumput laut (kali/ } \\
\text { minggu) (Seaweed control (time/ } \\
\text { weeks)) }\end{array}$ & 33.308 & 38.815 & .168 & .858 & .400 \\
\hline
\end{tabular}

Keterangan (Note):

a. Variabel dependen (Dependent variable) : Produksi rumput laut (Seaweed production) $\left(\mathrm{kg} / 3.000 \mathrm{~m}^{2}\right.$ ) 